$\mathrm{XX}$ Міжнародний симпозіум «Методи дискретних особливостей в задачах математичної фізики/Discrete Singularities Methods in Mathematical Physics», МДОЗМФ/DSMMPh-2021

УДК 532.517

MSC 76S05

\title{
Dimple generator of vortex structures
}

\author{
A.V. Voskobijnyk ${ }^{1}$, V.M. Turick ${ }^{2}$, O.A. Voskoboinyk ${ }^{1}$, V.A. Voskoboinick ${ }^{1}$ \\ ${ }^{1}$ Institute of hydromechanics NASU, Kyiv, Ukraine \\ ${ }^{2}$ NTUU “Igor Sikorsky Kyiv Polytechnic Institute”, Kyiv, Ukraine \\ E-mail: andrey.vsk@gmail.com
}

\begin{abstract}
The paper presents the results of experimental studies of the space-time characteristics of the velocity and pressure field inside a hemispherical dimple on a flat surface. The features of the formation and development of vortex structures generated inside the dimple, as well as their interaction with the streamlined surface of the dimple and the boundary layer were established. Integral, spectral and correlation characteristics of the field of velocity, dynamic and wall pressure fluctuations were obtained. The velocities and directions of transfer of large-scale vortex structures and small-scale vortices inside the dimple were determined. The frequencies of rotations and ejections of large-scale vortices, the frequencies of oscillations of the vortex flow inside the dimple and self-oscillations of the vortex structures of the shear layer, their subharmonics and harmonics of higher orders were established.
\end{abstract}

Key words: hemispherical dimple, visualization, velocity and pressure fluctuations, vortex structures, correlation, spectrum.

\section{Лунковий генератор вихрових структур}

\author{
А.В. Воскобійник ${ }^{1}$, В.М. Турик ${ }^{2}$, О.А. Воскобойник ${ }^{1}$, В.А. Воскобійник ${ }^{1}$ \\ ${ }^{1}$ Інститут гідромеханіки НАН України, Київ, Україна \\ ${ }^{2}$ НТТУ “Київський політехнічний інститут імені Ігоря Сікорського”, Київ, Україна \\ E-mail: andrey.vsk@gmail.com
}

\begin{abstract}
В роботі представлені результати експериментальних досліджень просторовочасових характеристик поля швидкості і тиску всередині напівсферичної лунки на плоскій поверхні. Установлено особливості формування і розвитку вихрових структур, які генерувалися всередині лунки, а також їх взаємодії з обтічної поверхнею лунки і прикордонним шаром. Отримано інтегральні, спектральні і кореляційні характеристики поля пульсацій швидкості, динамічного і пристінкового тиску. Визначено швидкості і напрями перенесення великомасштабних вихрових структур i дрібномасштабних вихорів усередині лунки. Установлено частоти обертання і викидів великомасштабних вихорів, частоти осциляцій вихрової течії всередині лунки i автоколивань вихрових структур зсувного шару, їх субгармоніки і гармоніки вищих порядків.
\end{abstract}

Ключові слова: напівсферична лунка, візуалізація, пульсації швидкості та тиску, вихрові структури, кореляція, спектр.

\section{1. Ветуп}

Одним з головних шляхів підвищення економічності енергоустановок є вдосконалення теплообмінного обладнання за допомогою впровадження ефективних способів передачі тепла. Особливий інтерес викликають методи інтенсифікації теплообміну, які впливають на пристінну область примежового шару обтічної поверхні. Інтенсифікація тепло- і масообміну, здійснюється активними (використання додаткової енергії) і пасивними методами. Серед пасивних методів широке застосування

(с) Воскобійник А.В., Турик В.М., Воскобойник О.А., Воскобійник В.А., 2021 
отримали сферичні заглиблення (лунки), як генератори вихорів. Залежно від швидкості потоку і відносної глибини сферичних лунок реалізується ряд режимів течії (безвідривного і відривного ламінарного обтікання сферичних лунок, а також перехідного і турбулентного відривного обтікання лунок) [1]. Усередині лунок, в залежності від режимів течії, глибини і форми кромок генеруються симетричні і асиметричні вихрові структури, поворотні і циркуляційні течії. На кормових стінках спостерігаються області підвищених тисків, а в ближньому сліді лунок формуються області знижених тисків там, де вихрові структури викидаються з лунок в примежовий шар. Залежно від умов обтікання всередині сферичних лунок спостерігається біфуркація вихрового течії [2]. Складна вихрова течія всередині одиночних сферичних лунок і лункових поверхонь і періодичні викиди вихорів у примежовий шар генерують інтенсивні пульсації швидкості і тиску. Тому вивчення просторово-часових і спектрально-кореляційних характеристик вихрової течії над лунковими поверхнями і вібрацій обтічних конструкцій дозволяють виявити характерні особливості течії в лунці.

Мета експериментальних досліджень - визначити особливості формування та розвитку вихрових структур, вивчаючи просторово-часові характеристики поля швидкості і тиску всередині напівсферичної лунки, яку зроблено на гідравлічно гладкій пласкій поверхні.

\section{2. Експериментальний стенд і методика досліджень}

Експерименти проводилися в гідродинамічному лотку довжиною 16 м, шириною 1 м і глибиною 0.8 м. Вимірювальна ділянка була обладнана засобами та апаратурою реєстрації характеристик потоку, координатними пристроями і розташовувався на відстані 8.0 м від вхідної частини лотка. В якості обтічної поверхні використовувалася гідравлічно гладка пластина 3 полірованого органічного скла товщиною $0.01 \mathrm{M}$, шириною $0.5 \mathrm{м}$ і довжиною $2.2 \mathrm{м}$. Передній і кормовий край пластини були заокруглені для створення умов їі безвідривного обтікання. На відстані $x=0.8$ м від носка пластини була зроблена напівсферична лунка діаметром $d=0.1$ м. Пластина була встановлена в вимірювальній ділянці гідродинамічного лотка паралельно його поверхні на висоті 0.1 м від дна лотка і 0.3 м від поверхні потоку. При проведенні досліджень швидкість течії $(U)$ змінювалася від $0.01 \mathrm{~m} / \mathrm{c}$

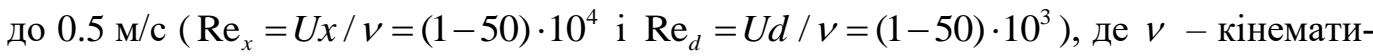
чний коефіцієнт в'язкості води.

Пульсації пристінного і динамічного тиску вимірювалися мініатюрними датчиками пульсацій тиску, які були виготовлені на базі п'єзокерамічних чутливих елементів. Діаметр чутливої поверхні датчиків був $d_{s}=1.3 \cdot 10^{-3}$ м і $1.6 \cdot 10^{-3}$ м. Датчики пульсацій пристінного тиску встановлювалися врівень з обтічної поверхнею, не порушуючи структуру потоку (рис. 1а). Датчики пульсацій динамічного тиску, у вигляді кореляційного блоку $з$ двох датчиків закріплювалися на добре обтічній державці та встановлювалися над обтічною поверхнею (рис. 1б). Датчики знаходилися один над іншим на відстані $0.05 d$, а їх чутливі елементи орієнтувалися назустріч потоку.

Плівкові одно і двокомпонентні термоанемометри фірми "Disa Electronics" використовувалися для вимірювань полів швидкості. Добре обтічні державки 3 датчиками встановлювалися на координатний пристрій. Цей пристрій дозволяв пере- 
XX Міжнародний симпозіум «Методи дискретних особливостей в задачах математичної фізики/Discrete Singularities Methods in Mathematical Physics»,

\section{МДОЗМФ/DSMMPh-2021}

міщати датчики в трьох взаємно перпендикулярних напрямках 3 кроком $10^{-5}$ м. У дослідженнях застосовувалися як поодинокі датчики, так і блок з декількох датчиків. Блок складався 3 однокомпонентного термоанемометра, під яким на відстані $0.05 \mathrm{~d}$ розташовувався двокомпонентний термоанемометр (див., рис. 1a). Процедура обробки і аналізу первинних сигналів датчиків представлена в роботах $[3,4]$.

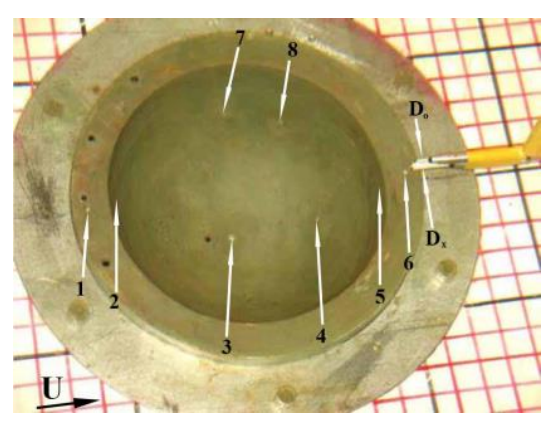

a

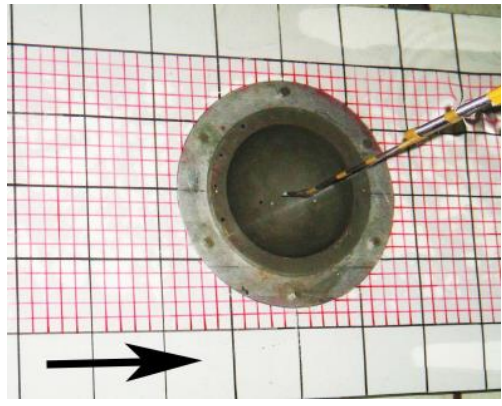

6

Рис. 1. Розташування датчиків пульсацій пристінного тиску та плівкових термоанемометрів (а) і датчиків пульсацій динамічного тиску (б).

\section{3. Результати досліджень}

Відповідно до розробленої програми і методики проведення експериментальних досліджень спочатку проводилася візуалізація течії і в іiі характерних областях вимірювалися поля швидкості та тиску. Візуалізація течії над пластиною виконувалася підведенням барвників через мініатюрні трубочки, закріплені в державках координатних пристроїв. Візуалізація на поверхні виконана нанесенням контрастних водорозчинних покриттів і підведенням барвників через отвори. Для реєстрації картин візуалізації використовувалася цифрова відео- і фотоапаратура, а результати досліджень оброблялися та аналізувалися за допомогою комп'ютерної графічної станції.

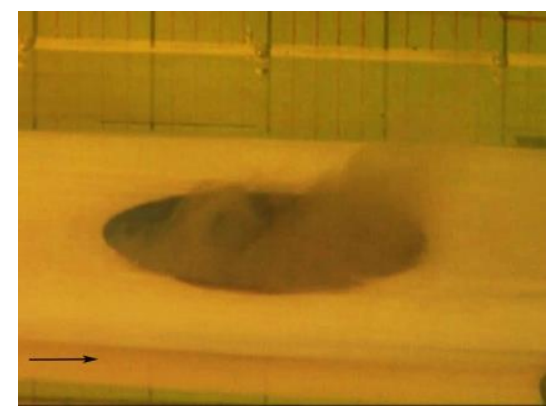

a

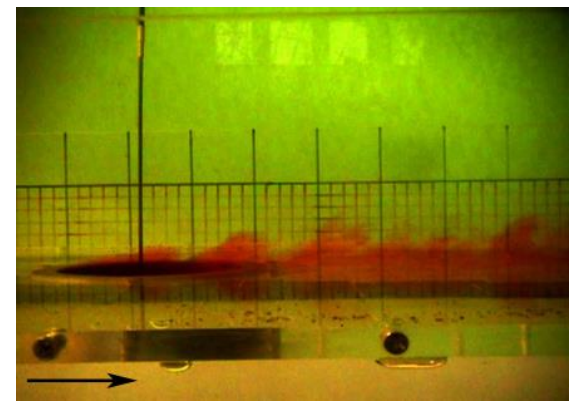

6

Рис. 2. Викид асиметричної вихрової структури назовні з лунки (а) та переніс вихрових структур у сліді лунки (б).

Візуалізація показала, що за швидкістю течії до 0.02 м/с обтікання лунки безвідривне. Зі збільшенням швидкості $\left(0.03 \mathrm{~m} / \mathrm{c}, \mathrm{Re}_{d}=3000\right)$ всередині лунки з'являлася відривна область поблизу передньої кромки, і зароджувалася циркуляційна 
течія, яка посилювалася з ростом швидкості обтікання. У лунці формувалася симетрична аркоподібна або підковоподібна вихрова структура $з$ двома фокусами на дні лунки поблизу кормової стінки.

Зі збільшенням швидкості обтікання більше 0.17 м/с $\quad\left(\operatorname{Re}_{x}>1.4 \cdot 10^{5} \mathrm{i}\right.$ $\left.\operatorname{Re}_{d}>1.7 \cdot 10^{4}\right)$ вихрова структура ставала асиметричною та відбувався періодичний викид вихрового середовища назовні 3 лунки 3 безрозмірною частотою $S t=f d / U=(0.04-0.06)$. Викид спостерігався по черзі над протилежними сторонами лунки $[2,5,6]$. На рис. 2 представлені фотографії викиду контрастного водорозчинного покриття назовні з напівсферичної лунки і перенесення кольорового чорнила в примежовому шарі над пластиною для турбулентного режиму течії $\left(\operatorname{Re}_{x}=2 \cdot 10^{5} \mathrm{i} \operatorname{Re}_{x}=2.5 \cdot 10^{4}\right)$. Усередині лунки генерувалися великомасштабні вихрові структури, які періодично викидалися над однією з бічних сторін кормової стінки, як показано на рис. $2 \mathrm{a}$.

Викинуті вихрові структури (рис. 2б) на відстані близько діаметра лунки досягали зовнішньої області примежового шару $(\delta \approx 0.2 d)$ і переносилися вниз за потоком від напівсферичної лунки зі швидкістю, яка близька до швидкості течії. Ці структури на відстані близько (8-10) $d$ руйнувалися і примежовий шар поступово відновлювався $[4,6]$.
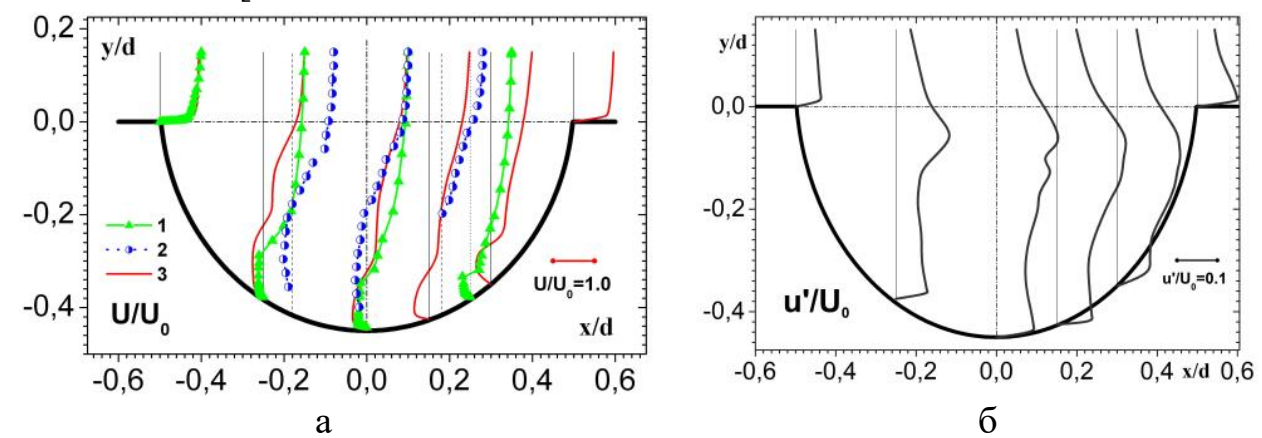

Рис. 3. Осереднені поздовжні швидкості всередині лунки (а) та їх пульсаційні складові (б).

Характерною особливістю профілів швидкості всередині напівсферичної лунки були перегини, які з'являлися для перехідного і турбулентного режимів течії (рис. 3). Вони свідчили про наявність нестійкостей в зсувних шарах і формуванні циркуляційної течії. Крива 1 на рис. За представляє результати роботи [1], крива 2 - результати роботи [7] і крива 3 - наші виміри. У верхній частині лунки поблизу шару змішування спостерігалися значні швидкості у напрямку руху, а в придонній iii частині мала місце зворотна течія, утворюючи циркуляцію рідини всередині лунки. Профілі середньоквадратичних значень пульсацій поздовжньої швидкості (рис. 3б) мали більш виражені перегини, особливо в місцях сполучення зсувного шару з течією в лунці. Максимальні рівні пульсацій швидкості всередині лунки мали місце поблизу кормової стінки, де відбувалося взаємодія вихрових структур зсувного шару з поверхнею лунки. Мінімальні значення пульсацій швидкості спостерігалися в передній частині лунки та в iї придонній області. 
XX Міжнародний симпозіум «Методи дискретних особливостей в задачах математичної фізики/Discrete Singularities Methods in Mathematical Physics», МДОЗМФ/DSMМРh-2021
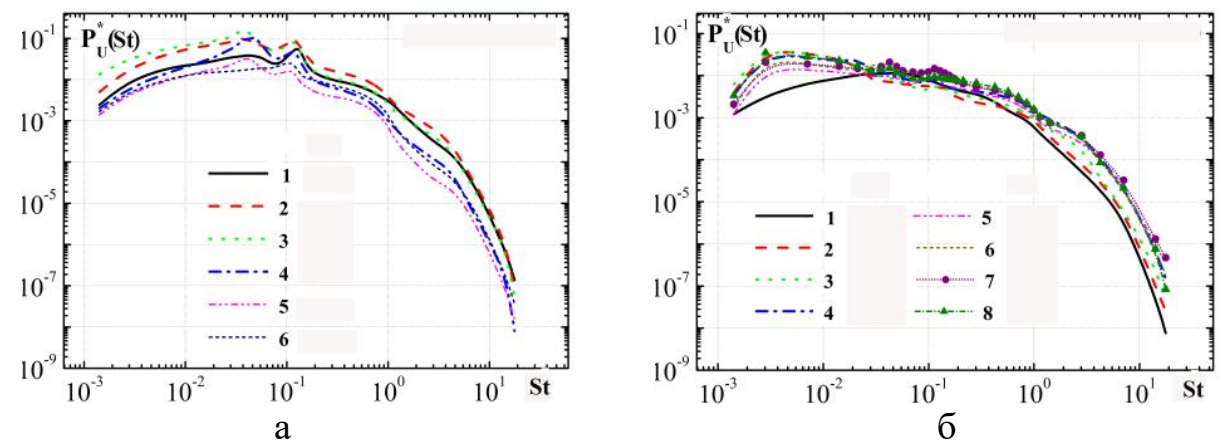

Рис. 4. Спектри пульсацій поздовжньої швидкості всередині лунки (а) та над обтічною поверхнею пластини та лунки (б).

На рис. 4а показані значення спектральних щільностей потужності пульсацій поздовжньої швидкості $P_{U}^{*}(S t)=P(S t) / U d \quad$ в залежності від числа Струхаля $S t=f d / U$. Виміри проводилися в серединному перерізі лунки на різній глибині для числа Рейнольдса $\operatorname{Re}_{d}=2 \cdot 10^{4}$. Крива 1 відповідала вимірам в точці 3 координатою $y / d=0$; крива $2-y / d=-0.05$; крива $3-y / d=-0.13$; крива $4-y / d=-0.20$; крива 5 - $y / d=-0.30$ і крива $6-y / d=-0.40$. На рівні поверхні пластини $(y / d=0)$ спектральна щільність потужності мала два підйому на частоті близько 42 Гц $(S t \approx 0.06)$ і 82 Гц $(S t \approx 0.11)$, але переважним $є$ друга. Із заглибленням в лунку спектральні щільності на низьких частотах досягали найбільшого рівня на глибині $y / d=-0.13$. 3 наближенням до місця розташування ядра квазістійкого великомасштабного вихору всередині лунки відбувалося зменшення високочастотної і низькочастотної частини спектра.

На рис. $4 б$ показані зміни спектральних густин потужності пульсацій поздовжньої швидкості уздовж осі пластини з напівсферичної лункою на висоті $y / d=0.05$ над поверхнею пластини. Тут кривої 1 позначені результати для перетину $x / d=-$ 1.75 ; кривої $2-x / d=-0.50$ (початок лунки); кривої $3-x / d=-0.25$; кривої 4 $x / d=0.15$; кривої $5-x / d=0.30$; кривої $6-x / d=0.50$ (кінець лунки); кривої 7 $x / d=1.05$ і кривої $8-x / d=2.20$. Вплив лунки на прикордонний шар не виявлялося лише для одного виміряного перетину $x / d=-1.75$ (крива 1). На рівні переднього краю лунки відзначалося підвищення спектральних рівнів в області дуже низьких частот порядку (2-4) Гц або $S t=(0.003-0.005)$. Таке наповнення спектра спостерігалося над всією передньою частиною лунки і обумовлено низькочастотним модулюючим коливанням вихрової течії всередині лунки. Однак амплітуда низькочастотних пульсацій з віддаленням від переднього краю лунки зменшувалася, а високочастотних - навпаки зростала. 3 просуванням над пластиною від переднього краю лунки до їі кормовій частині виросли спектральні рівні на частотах (40-43) Гц i $(80-85)$ Гц $(S t=(0.04-0.06)$ i $S t=(0.10-0.11))$.

Спектральні щільності потужності пульсацій пристінного тиску $P_{q}^{*}(S t)=P(S t) U / d q^{2}$ в залежності від числа Струхаля, показані на рис. 5а для чисел Рейнольдса $\operatorname{Re}_{x}=8 \cdot 10^{4}$ i $\operatorname{Re}_{d}=10^{4}$. Тут номера кривих відповідали номерам 
датчиків пульсацій пристінного тиску, які показані на рис. 1а. Перед поглибленням спектр пульсацій тиску мав характер, який був типовим для пульсацій пристінного тиску турбулентного прикордонного шару $[5,8]$. На передній та придонній частині лунки спостерігалося зменшення низькочастотних складових спектру та збільшення високочастотних компонент, які генерувалися дрібномасштабними вихорами. На кормовій стінці лунки суттєво збільшилися пульсації пристінного тиску в усьому досліджуваному діапазоні частот.
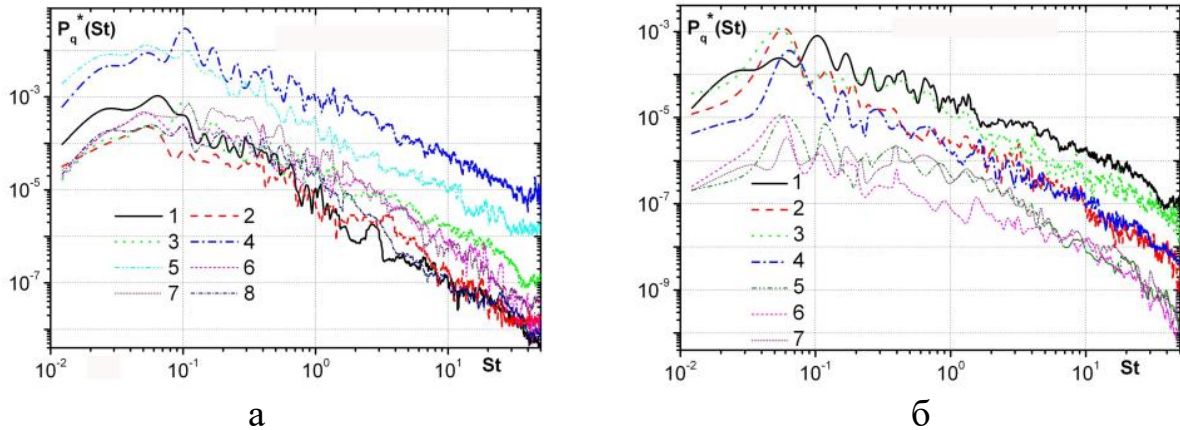

Рис. 5. Спектри пульсацій пристінного тиску в околі лунки (а) та пульсацій динамічного та пристінного тиску по глибині лунки (б).

Спектральні щільності потужності пульсацій динамічного і пристінного тиску, виміряні по вертикальній осі лунки з координатами $(x / d=0 ; y / d=\operatorname{var} ; z / d=0)$ i нормовані швидкісним напором $q=\rho U^{2} / 2$, показані на рис. 5б. Датчики пульсацій динамічного тиску знаходилися над датчиком пульсацій пристінного тиску № 3 (рис. 1а). Крива 1 - це пульсації пристінного тиску на дні лунки (датчик № 3, координати $x=0 ; y=-0.5 d ; z=0)$. Крива 2 - це пульсацій динамічного тиску на глибині $y / d=-0.45$; крива $3-y / d=-0.40$; крива $4-y / d=-0.38$; крива $5-$ $y / d=-0.35$; крива $6-y / d=-0.33$ і крива $7-y / d=-0.30$. Максимальна інтенсивність пульсацій тиску на дні лунки спостерігалася на частоті обертання великомасштабного вихору $S t \approx 0.1 .3$ віддаленням від поверхні лунки збільшуються дискретні складові спектру пульсацій динамічного тиску на частоті викиду великомасштабних вихрових структур назовні з лунки на частоті $S t \approx 0.05$.

\section{Висновки}

Для ламінарного режиму течії спостерігалося безвідривне обтікання лунки. Для перехідного режиму в напівсферичній лунці генерувалися симетричні вихрові структури у вигляді підковоподібних вихорів 3 джерелами у придонній частині лунки. Коли наступав турбулентний режим течії, то великомасштабна вихрова структура усередині лунки набувала асиметричної форми. IІЇ джерело знаходилося на одній з бічних передніх сторін лунки, а викид іiі назовні з лунки у вигляді поздовжнього вихору спостерігався над протилежною кормовою стінкою лунки. Періодично формування та викид цього вихору спостерігалися то над однією бічною стороною придонної передньої частини лунки та над протилежною кормовою частиною лунки, то над іншими, набуваючи біфуркаційного характеру. В лунці спостерігалися низькочастотні модулюючі коливання з частотою $S t \approx 0.003$, викид ве- 
XX Міжнародний симпозіум «Методи дискретних особливостей в задачах математичної фізики/Discrete Singularities Methods in Mathematical Physics», МДОЗМФ/DSMМPh-2021

ликомасштабного вихору назовні з лунки з частотою $S t \approx 0.05$ та його обертання 3 частотою $S t \approx 0.1$. Ці тональні компоненти спектру були зареєстровані у пульсаціях поздовжньої швидкості, динамічного та пристінного тиску. 3 віддаленням більше 10 діаметрів лунки примежовий шар над пластиною відновлювався.

\title{
ЛІТЕРАТУРА
}

1. Leontiev A.I., Kiselev N.A., Vinogradov Yu.A., et al. Experimental investigation of heat transfer and drag on surfaces coated with dimples of different shape. International Journal of Thermal Sciences. 2017. Vol. 118. P. 152-167.

2. Isaev S.A., Leontiev A.I., Baranov P.A., Usachov A.E. Bifurcation of vortex turbulent flow and intensification of heat transfer in a hollow. Doklady Physics. 2000. Vol. 45, № 8. P. 389-391. https://doi.org/10.1134/1.1310729

3. Voskoboinick V.A., Grinchenko V.T., Makarenkov A.P. Correlation characteristics of a wall pressure fluctuation field in a turbulent boundary layer induced by a longitudinal flow along a flexible extended cylinder. International Journal of Fluid Mechanics Research. 2003. Vol. 30, № 6. P. 644-650.

4. Voskoboinick V.A., Voskoboinick A.A., Turick V.N., Voskoboinick A.V. Space and time characteristics of the velocity and pressure fields of the fluid flow inside a hemispherical dimple generator of vortices. J. Eng. Physics and Thermophysics. 2020. Vol. 93, № 5. P. 1205-1220. https://doi.org/10.1007/s10891-020-02223-3

5. Voskoboinick V., Kornev N., Turnow J. Study of near wall coherent flow structures on dimpled surfaces using unsteady pressure measurements. Flow Turbulence Combust. 2013. Vol. 90, № 4. P. 709-722. https://doi.org/10.1007/s10494-012-9433-9

6. Voskoboinick V.A., Turick V.N., Voskoboinyk O.A. et al. Influence of the Deep Spherical Dimple on the Pressure Field under the Turbulent Boundary Layer. Advances in Computer Science for Engineering and Education. ICCSEEA 2018. Advances in Intelligent Systems and Computing. 2019. Vol754. P. 23-32. https://doi.org/10.1007/978-3-319-91008-6_3

7. Terekhov V.I., Kalinina S.V., Mshvidobadze Yu.M. Heat Transfer Coefficient and Aerodynamic Resistance on a Surface with a Single Dimple. Journal of Enhanced Heat Transfer. 1997. Vol. 4, № 4. P. 131-145.

8. Voskoboinick V., Voskoboinick A., Voskoboinyk O., Turick V. Dimple generators of longitudinal vortex structures. Theory, Applications and Numerical Methods. IntechOpen: London, 2019. P. 1-12. https://doi.org/10.5772/intechopen.83518

Надійшла 20.04.2021.

\section{Луночный генератор вихревых структур}

\author{
А.В. Воскобойник ${ }^{1}$, В.Н. Турик ${ }^{2}$, А.А. Воскобойник ${ }^{1}$, В.А. Воскобойник ${ }^{1}$ \\ ${ }^{1}$ Институт гидромеханики НАН Украины, Киев, Украина \\ ${ }^{2}$ НТТУ “Киевский политехнический институт имени Игоря Сикорского”, Киев, Украина \\ E-mail: andrey.vsk@gmail.com
}

В работе представлены результаты экспериментальных исследований пространственно-временных характеристик поля скорости и давления внутри полусферической лунки на плоской поверхности. Особенности вихревого движения исследова- 
лись с помощью визуализации течения и измерения гидродинамических характеристик поля скорости и давления. Были исследованы поля скорости и давления над обтекаемыми поверхностями с помощью группы пленочных термоанемометров и пьезокерамических датчиков динамического давления. Поле пульсаций давления на обтекаемых поверхностях исследовались с помощью миниатюрных датчиков пульсаций давления, которые устанавливались заподлицо с обтекаемой поверхностью. Результаты визуальных исследований показали, что для ламинарного режима течения наблюдалось безотрывное обтекание лунки. Для переходного режима в полусферической лунке генерировались симметричные вихревые структуры в виде аркообразных вихрей с источниками в придонной части лунки. Когда наступал турбулентный режим течения, то крупномасштабная вихревая структура внутри лунки приобретала асимметричную форму. Ее источник находился на одной из боковых передних сторон лунки, а выброс ее наружу из лунки наблюдался над противоположной кормовой стенкой лунки в виде продольного вихря. Периодически формирование и выброс этого вихря наблюдались то над одной боковой стороной придонной передней части лунки и над противоположной кормовой частью лунки, то над другими, принимая бифуркационный характер. Таким образом, установлены особенности формирования и развития вихревых структур, которые генерировались внутри лунки, а также их взаимодействия с обтекаемой поверхностью лунки и пограничным слоем. Получены интегральные, спектральные и корреляционные характеристики поля пульсаций скорости, динамического и пристеночного давления. Определены скорости и направления переноса крупномасштабных вихревых структур и мелкомасштабных вихрей внутри лунки. Установлены частоты вращения и выбросов крупномасштабных вихрей, частоты осцилляций вихревого течения внутри лунки и автоколебаний вихревых структур сдвигового слоя, их субгармоники и гармоники высших порядков.

Ключевые слова: полусферическая лунка, визуализация, пульсации скорости и давления, вихревые структуры, корреляция, спектр. 